\title{
Catalyst Recovery, Regeneration and Reuse during Large-Scale Disinfection of Water Using Photocatalysis
}

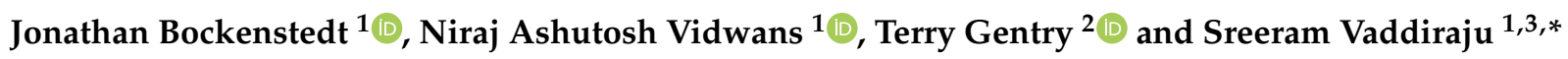 \\ 1 Artie McFerrin Department of Chemical Engineering, Texas A\&M University, College Station, TX 77843, USA; \\ alexbockenstedt@tamu.edu (J.B.); nirajvidwans@tamu.edu (N.A.V.) \\ 2 Department of Soil and Crop Sciences, Texas A\&M University, College Station, TX 77843, USA; \\ tigentry@tamu.edu \\ 3 Department of Materials Science \& Engineering, Texas A\&M University, College Station, TX 77843, USA \\ * Correspondence: sreeram.vaddiraju@tamu.edu; Tel.: +1-979-862-1615
}

Citation: Bockenstedt, J.;

Vidwans, N.A.; Gentry, T.;

Vaddiraju, S. Catalyst Recovery,

Regeneration and Reuse during

Large-Scale Disinfection of Water

Using Photocatalysis. Water 2021, 13,

2623. https://doi.org/10.3390/

w13192623

Academic Editor: Jiangyong Hu

Received: 28 August 2021

Accepted: 21 September 2021

Published: 24 September 2021

Publisher's Note: MDPI stays neutral with regard to jurisdictional claims in published maps and institutional affiliations.

Copyright: (C) 2021 by the authors. Licensee MDPI, Basel, Switzerland. This article is an open access article distributed under the terms and conditions of the Creative Commons Attribution (CC BY) license (https:/ / creativecommons.org/licenses/by/ $4.0 /)$.

\begin{abstract}
The deployment of photocatalysis for remediation of water has not yet been realized, although laboratory-scale studies have demonstrated promise. Accomplishing this requires the development of photocatalysis as a process, including studying its efficiencies in remedying water when high volumes of water are processed, and addressing the recovery, possible regeneration and reuse of the photocatalysts. To that end, this work is aimed at demonstrating the use of a custom-built mobile platform for disinfecting large quantities of water. The benchtop platform built is capable of processing 15.14 L (4 gallons) per minute of water, with possibility for further scale-up. Preliminary studies on the catalyst recovery, regeneration and reuse via gravity-assisted settling, centrifugation and air plasma treatment indicated that $77 \%$ of Aeroxide ${ }^{\circledR} \mathrm{P} 25$ titania $\left(\mathrm{TiO}_{2}\right)$ nanoparticle and $57 \%$ of porous $\mathrm{TiO}_{2}$ nanowire photocatalysts could be recovered and regenerated for further use. Overall, this study indicated that process improvements, including increasing the kinetics of the photocatalysis, and optimization of the efficacies of the catalyst recovery and regeneration processes will make it useful for water remediation on any scale. More importantly, the portable and flexible nature of the benchtop photocatalysis system makes it amenable for use in conjunction with existing technologies for remedying large quantities of water.
\end{abstract}

Keywords: water; disinfection; benchtop; photocatalysis; titania; E. coli; catalyst recovery; catalyst regeneration; dark repair

\section{Introduction}

Drinking water and wastewater treatment, specifically disinfection, has been studied extensively to meet the challenges associated with changes to both the quality of wastewater and the regulations of various government agencies (e.g., US Environmental Protection Agency) [1-3]. In order to meet the regulations, new and effective wastewater disinfection technologies or treatment trains are being developed [1]. Contextually, the motivation to overcome drawbacks associated with homogeneous-phase advanced oxidative processes (AOPs) led researchers to study photocatalysis-based AOPs over the last three decades [2,4-6]. Tremendous progress has been achieved with the design and development of photocatalyst chemistries, and in the development of an understanding of the mechanisms underlying photocatalysis-assisted water treatment [2,7-9]. However, efforts aimed at making process improvements for implementing photocatalysis on a large-scale in water remediation have not been on par with the above-mentioned improvements [2,7]. A recent commentary by Ezra L. Cates clearly emphasizes the need for process improvements to render photocatalysis viable for large-scale applications [7].

A review of the literature shows that a few attempts have been made for scaling up the photocatalysis process to pilot scale. Some of these attempts include the following: the use of hybrids composed of three-dimensional graphene and black titania by 
Zhao et al. [10], the use of immobilized titania and compound parabolic (solar) collectors by Alrousan et al. [11], the use of helical supports in the annular space of a UV reactor by Yu et al. [12] and the use of slurry-type tubular photocatalytic reactor by Saran et al. [13]. A key aspect that needs to be included in pilot-scale studies is the ability to continuously recover and reuse the photocatalysts $[7,14]$, an aspect that has not been studied extensively. In the literature, a few different approaches employed to tackle this problem are reported. Kacem et al. [15] and Pozzo et al. [16], for example, attempted to use catalysts immobilized on reactor walls or some granular substrates to get around the problem of postprocessing water for the separation of photocatalyst. However, due to the low exposure of the catalyst to the activating light irradiation, these configurations tend to operate with mass transfer limitations [5]. Other studies, including those by Chong et al. [17] and Ochuma et al. [18] demonstrate the use of sedimentation and flocculation to recover the catalysts in a microparticulate form. A third proposed solution to the problem of catalyst separation is the use of membrane photocatalytic reactors, a type of hybrid reactor which operates continuously by retaining the catalyst within the reactor while passing the water through a microfiltration/nanofiltration membrane [19]. While these hybrid reactors show some promise in retaining the catalyst while removing certain organic compounds, their implementation on a large scale is hindered due to the vulnerability of the membranes to degradation upon exposure to UV radiation and the high amounts of reactive oxygen species produced by the photocatalyst, as well as membrane fouling owed to catalyst particles blocking the membrane pores [20]. Biofouling of membranes could potentially be a major problem, especially when photocatalysis is implemented for disinfecting water. Furthermore, there have been reports of photocatalyst activity being lost during the course of the photocatalysis process. While there have been some studies investigating catalyst reactivation in the context of air purification by photocatalysis [21-23], information on reactivation of photocatalysts in the context of photocatalytic disinfection of water is lacking.

In this regard, the aim of the research presented in this paper is two-fold: (i) build a pilot-scale mobile unit for the disinfection of water using photocatalysis; (ii) demonstrate the ability to recover and reuse, at least partially, the photocatalyst from the pilot-scale mobile unit following the disinfection of water. Specifically, the inactivation of Escherichia coli (E. coli) from water using ultraviolet-A (UV-A) light sources for photoactivating $\mathrm{TiO}_{2}$ nanowire and nanoparticle photocatalysts, followed by the recovery, regeneration and reuse of the photocatalyst is discussed in detail in this paper. While $\mathrm{TiO}_{2}$ was specifically chosen as the material in this study owing to its wide use in photocatalysis $[24,25]$ and its availability from commercial vendors (e.g., Aeroxide ${ }^{\circledR} \mathrm{P}^{2} 5 \mathrm{TiO}_{2}$ nanoparticles by Evonik), UV-A light sources were specifically chosen to delineate the effects of UV-assisted disinfection and photocatalysis-assisted disinfection. Such a delineation was not possible when UV-C light sources were employed, as UV-C light by itself is a potent disinfectant [26].

\section{Materials and Methods}

All the valves, fittings and piping required for constructing the mobile benchtop photocatalysis system were obtained from Swagelok ${ }^{\circledR}$ (Swagelok Southeast Texas, Houston, TX, USA). In addition, a MultiPure ${ }^{\circledR}$ UV water purifier was procured from Atlantic UV corporation ${ }^{\circledR}$ (Hauppauge, NY, USA) and integrated into the photocatalysis system. A Bactiquant ${ }^{\circledR}$ Water bacteria quantification system obtained from Mycometer, Inc. (Tampa, FL, USA) was also added for the rapid assessment of E. coli inactivation. This served as a supporting method in the enumeration of viable bacteria, which was also performed using the spiral plating method (using an IUL Eddy Jet 2W spiral plater (IUL S.A., Barcelona, Spain), described below). GE ${ }^{\circledR}$ inline filters (GE appliances, Rapid City, ND, USA) served dual purpose of filtering both incoming water and water after its disinfection. Magnetic utility drive pumps (from Danner Manufacturing, Inc., Islandia, NY, USA) helped in moving water continuously through the photocatalysis system. Tanks for storage of both incoming water and disinfected water were obtained from Tamco ${ }^{\circledR}$ Industries (United 
States Plastic Corp., Lima, OH, USA). An electronic overhead mechanical stirrer from Velp Scientific, Inc. (Bohemia, NY, USA) helped in mixing the inlet water containing E. coli with the photocatalysts.

Two different types of $\mathrm{TiO}_{2}$ photocatalysts were employed in this study. Porous $\mathrm{TiO}_{2}$ nanowires were obtained from Advanced Energy Materials, LLC (Louisville, KY, USA), while Aeroxide ${ }^{\circledR} \mathrm{P} 25 \mathrm{TiO}_{2}$ nanoparticles were obtained from Acros Organics (Thermo Fisher Scientific, NJ, USA). $\mathrm{TiO}_{2}$ nanowires were synthesized by atmospheric pressure plasma jets using a solvo-plasma approach as reported previously [27-29].

The growth of E. coli for the disinfection experiments was performed using the following procedure. Aliquots of $E$. coli (ATCC ${ }^{\circledR} 51739$ ) preserved in glycerol stock at $-80{ }^{\circ} \mathrm{C}$ were transferred into $250 \mathrm{~mL}$ of nutrient broth (LB Broth Miller) aseptically. The culture was then incubated at $37^{\circ} \mathrm{C}$ and slowly shaken using an orbital shaker for $18-20 \mathrm{~h}$. This suspension was then centrifuged at 3000 RCF for $10 \mathrm{~min}$. The supernatant was removed, leaving behind only the separated cells. Nanopure water was then added to the centrifuge tube containing the cells and the suspension was vortexed to wash the cells. The suspension was centrifuged again at $3000 \mathrm{RCF}$ for $10 \mathrm{~min}$. The cells were then washed another time using the same procedure outlined above. The supernatant of the final wash was removed and replaced with $250 \mathrm{~mL}$ Nanopure water and mixed, creating a resuspension of $\sim 10^{8} \mathrm{CFU} / \mathrm{mL}$ of $E$. coli.

The procedure employed to study the efficacy of the benchtop system is explained in the results and discussion section, along with the results obtained. To compare the efficiency of the benchtop photocatalysis system in disinfecting E. coli, small-scale disinfection experiments using quartz beakers as photocatalyst reactors were also performed using the following procedure. A $30 \mathrm{mg}$ aliquot of the catalyst was added to $29.7 \mathrm{~mL}$ of Nanopure water within a quartz beaker. This mixture was mixed for at least $2 \mathrm{~h}$. An aliquot $(0.3 \mathrm{~mL})$ of the E. coli suspension was added to the nanowire suspension and allowed to mix for at least $15 \mathrm{~min}$. For each photocatalysis run, the beaker was placed within $2.54 \mathrm{~cm}$ of the UV-A light source (SunLite ${ }^{\circledR} 20 \mathrm{~W}, 15$ Lumens Blacklight obtained from Sunlite, Brooklyn, NY, USA). The light source and the sample were placed within a cardboard box with the inside covered in aluminum foil. All samples were continuously mixed for the duration of the experiment.

To determine viable $E$. coli counts, $500 \mu \mathrm{L}$ samples were drawn at pre-determined time intervals. Serial dilutions were performed as needed, vortexing each dilution to ensure complete mixing, and spiral plated on Brain Heart Infusion Agar using an IUL Eddy Jet $2 \mathrm{~W}$ spiral plater. The plates were then incubated for $24 \mathrm{~h}$ at $35^{\circ} \mathrm{C}$ following which colonies were counted using the IUL SphereFlash ${ }^{\circledR}$ automatic colony counter (IUL S.A., Barcelona, Spain) to enumerate the number of viable organisms at each time point.

Gravity-assisted settling and centrifugation and air plasma treatment were employed for the recovery and regeneration of the photocatalysts, respectively, in this study. These procedures, along with the results obtained, are also included in the results and discussion section. Brunauer, Emmett and Teller (BET) analysis was employed to determine the specific surface areas of various photocatalysts employed in this study. For the BET analysis the nitrogen adsorption-desorption isotherms were recorded at a bath temperature of 77.25 K using a Micromeritics ASAP 2020 Plus instrument (Micromeritics, Norcross, GA, USA). A JEOL JSM-7500F FE-SEM microscope (JEOL USA, Inc., Peabody, MA, USA) was used to study the morphologies of the photocatalysts before and after their use in E. coli inactivation. A Jenway $6705 \mathrm{UV} /$ Visible scanning spectrophotometer (Cole-Parmer, Vernon Hills, IL, USA) was used to obtain ultraviolet-visible (UV-Vis) spectra of the photocatalyst suspensions.

\section{Results and Discussion}

The benchtop system constructed for processing $15.14 \mathrm{~L}$ (4 gallons) per minute (GPM) of water is depicted in Figure 1. The intent of ensuring that the unit could be fabricated and deployed for any type of stakeholders (e.g., households, farmers) led to the use of only com- 
mercially available components in its construction. Additional consideration in the design of the benchtop system was that it be leak-proof and easy to assemble/alter/disassemble. Therefore, the continuous loop flow system was designed using Swagelok ${ }^{\circledR} 3 / 8^{\prime \prime}$ diameter stainless steel pipes connected together via Swagelok ${ }^{\circledR}$ and national pipe thread (NPT) connections. As shown in Figure 1, the system is composed of a series of $\mathrm{GE}^{\circledR}$ inlet filters that offer the ability to filter incoming water. The system is flexible enough to allow changing the type of pretreatment filters used, depending on the quality of the inlet water. The use of $\mathrm{GE}^{\circledR}$ filter housings allows for numerous types of $\mathrm{GE}^{\circledR}$ filters to be interchanged into the system easily, giving greater filtration capabilities owing to the wide variety of $\mathrm{GE}^{\circledR}$ filters available. The current system employed three filters operating in series for pretreatment. These filters include a 5-micron sediment filter, a five-micron granular activated carbon filter, and a five-micron CTO (chlorine, taste and odor) carbon block filter. These three filters were chosen as they are commonly used in most reverse osmosis (RO) systems. Following filtration, water enters an $18.92 \mathrm{~L}$ (five-gallon) inlet tank that is equipped with an electronic overhead mechanical stirrer. Measured quantities of the photocatalysts are added to the water and stirred continuously before being sent into the MightyPure ${ }^{\circledR}$ UV purifier system. The UV purifier processes $15.14 \mathrm{~L}$ (4 gallons) per minute of water and provides high exposure to the UV lamp within. The purifier initially comes with a UV-C lamp encased within a quartz tube that spans the length of the purifier; however, the lamp is removable. For this study, the UV-C lamp was removed and replaced with UV-A LEDs ( $365 \mathrm{~nm}$, Waveform Lighting, Vancouver, WA, USA). After the water is processed in the UV system, the water is sent through a series of $\mathrm{GE}^{\circledR}$ filters and the disinfected water is collected in a second tank. The system is flexible in that each component discussed above, the inlet filtering system, the UV water treatment system and the outlet filtering system, could be bypassed upon necessity.

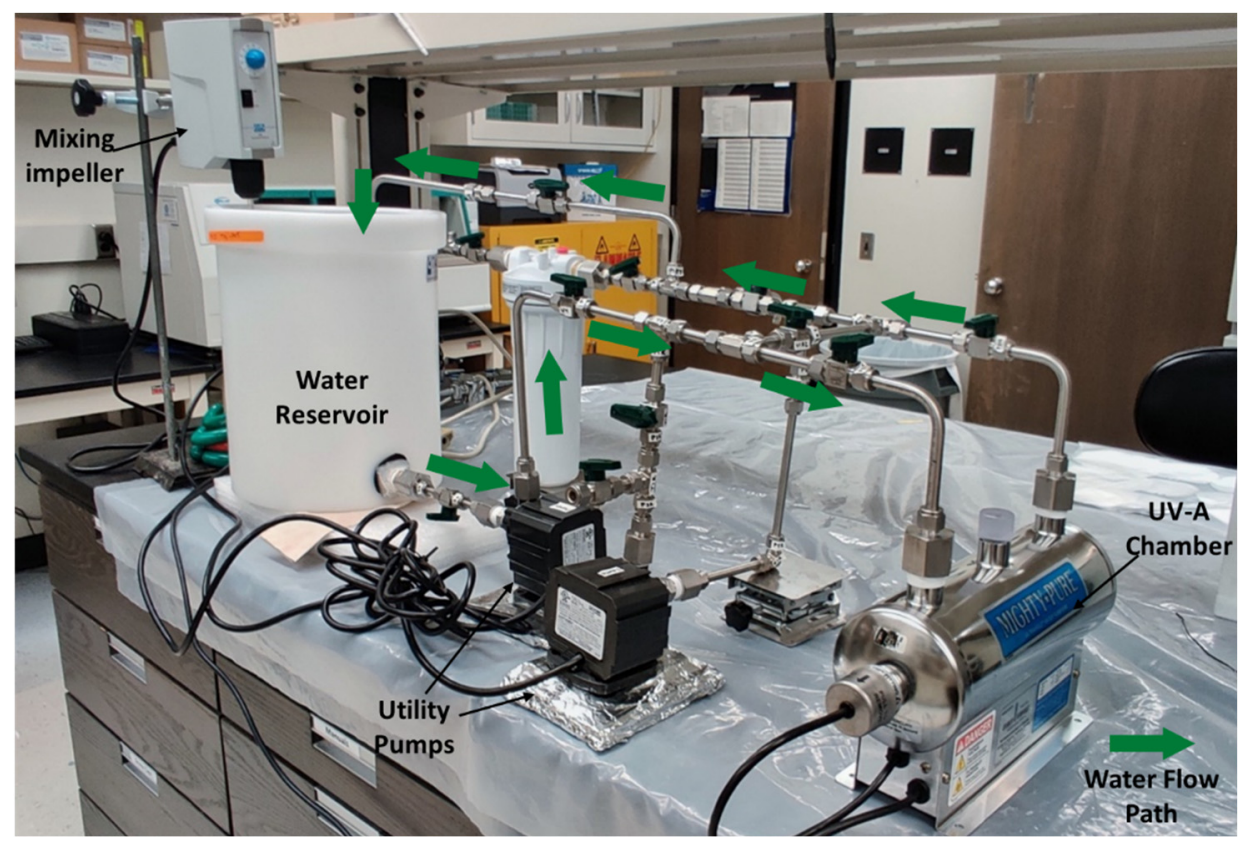

Figure 1. A picture of the benchtop water disinfection system built for processing $15.14 \mathrm{~L}$ (4 gallons) per minute of water. The setup is assembled from commercially available components, and could be mounted on a mobile stand for onsite disinfection of water at any desired location.

To study the kinetics of photocatalytic disinfection, the inlet filter was bypassed as the samples used in the experiment consisted only of Nanopure water, suspended E. coli and the appropriate photocatalyst. The outlet filter was also bypassed, as the experimentation aimed at obtaining the kinetics of the photocatalytic disinfection process did not necessitate the removal of the photocatalyst. In lieu of collecting the disinfected water in the outlet 
tank after each pass through the system, the outlet stream was fed back into the inlet tank. This allowed for a continuous cycling of the water and an increase in the residence time, i.e., an increase in the time the water containing both E. coli and photocatalyst was activated by UV-A light. In between multiple passes of water through the system, samples were intermittently gathered for spiral plate analysis of bacterial counts. At the end of the experimental run lasting a few hours, the water was finally collected for further analysis and experimentation. In short, the setup was run in a semicontinuous mode.

To begin the experiment, $6.5 \mathrm{~L}$ of Nanopure water was added to the inlet tank, along with $700 \mathrm{mg}$ of the desired photocatalyst. The suspension was mixed using the electronic overhead mechanical stirrer for $1.5 \mathrm{~h}$ to allow for proper dispersion of catalyst. $500 \mathrm{~mL}$ of resuspended bacteria aqueous solution was added to this nanowire dispersion in water and the resulting solution was mixed for another $30 \mathrm{~min}$. A sample was then drawn from this mixture to determine the initial concentration of $E$. coli. At this point, all the necessary valves were opened and the main pump was turned on, creating flow throughout the system. Once proper flow was established, the UV-A LEDs housed inside the UV system were activated and the timer started. Samples were then collected regularly every $30 \mathrm{~min}$. At the end of each experimental run, any remaining water was autoclaved to remove any remaining E. coli and recover the photocatalyst from water. For comparison purposes, control experiments involving using only UV-A exposure of E. coli suspended in water were performed using the same experimental procedure described above, with one notable exception. In the control studies (referred to as "clear control" in this manuscript), no photocatalyst was added to the water and consequently the initial mixing period was reduced to $30 \mathrm{~min}$.

The kinetics of E. coli inactivation in the benchtop system when Aeroxide ${ }^{\circledR}$ P25 nanoparticles and porous $\mathrm{TiO}_{2}$ nanowires were employed as photocatalysts are depicted in Figure 2. The experiments indicated that over $97 \%$ reduction in E. coli CFU is possible with an exposure time of 100 min when porous $\mathrm{TiO}_{2}$ nanowires were employed as the photo-catalyst. A faster, approximately 3-log, reduction in E. coli in a span of $50 \mathrm{~min}$ is possible when Aeroxide ${ }^{\circledR}$ P25 nanoparticles were employed for the photocatalysis. In both cases, the concentration of the photocatalysts in water was $0.1 \mathrm{~g} / \mathrm{L}$.

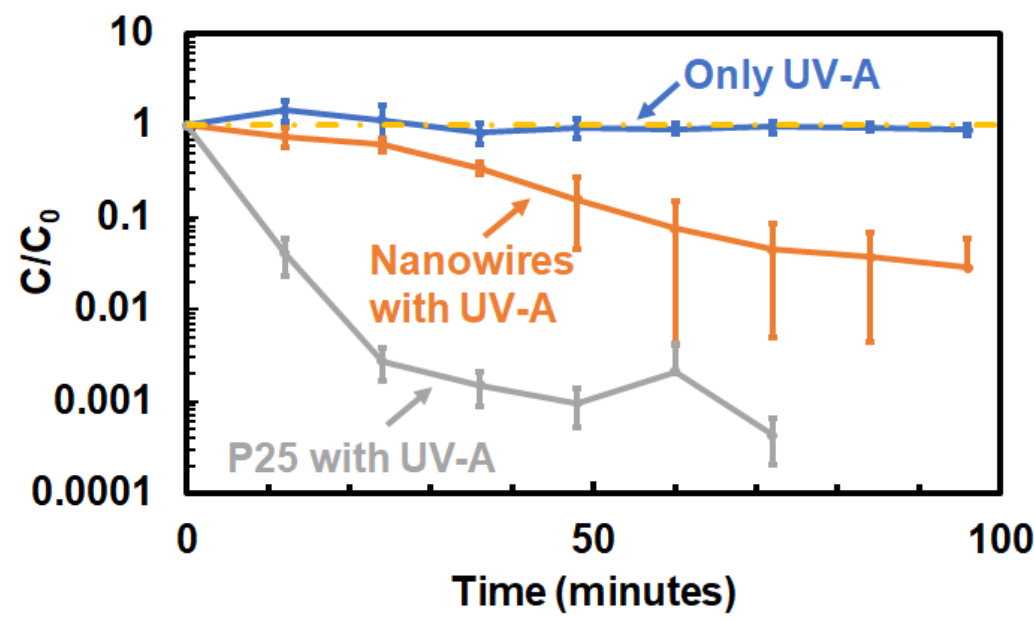

Figure 2. E. coli inactivation in the benchtop water disinfection system built for processing $15.14 \mathrm{~L}$ (4 gallons) per minute of water. The plot indicates that Aeroxide ${ }^{\circledR}$ P25 nanoparticles exhibit faster disinfection kinetics relative to that obtained using $\mathrm{TiO}_{2}$ porous nanowires. The photocatalyst concentration in both cases was $0.1 \mathrm{~g} / \mathrm{L}$.

These kinetics of E. coli inactivation were similar to those obtained when small-scale experimentations that involved the use of quartz beakers as photocatalyst reactors were employed [30] (See Figure S1 in the supplementary information provided). As shown in Figure S1, three different controls were employed in the small-scale studies. Exposure of E. coli in water to only UV-A light served as one control (clear control). The use of 
photocatalysts mixed with E. coli in water, without any UV-A activation of the nanowires, served as a second control (referred to as "dark control" in this manuscript). Negative control involved the use of no photocatalysts and no UV-A exposure to E. coli suspended in water. All the controls indicated that the presence of both UV-A light and the photocatalysts are necessary for E. coli inactivation. The results of the clear control experiment on the benchtop experiment (Figure 2) indicate the behavior is consistent with that of the smallscale experiments. These results are also in agreement with the disinfection kinetics reported in the literature. As can be seen in Figure S2 in the supplementary information, previous reports of photocatalytic disinfection of E. coli using $\mathrm{TiO}_{2}$ nanoparticles as catalysts show inactivation kinetics ranging from three orders of magnitude decrease in CFU in two hours to a significantly faster seven orders of magnitude decrease in CFU within 40 min depending upon the conditions of experiments [31-37]. The results from the smallscale experiments as well as on the benchtop setup fit well within that range, for both the Aeroxide ${ }^{\circledR} \mathrm{P} 25$ nanoparticles and the porous $\mathrm{TiO}_{2}$ nanowires. The wide range in kinetic data as shown in Figure S2 is likely a result of the varying experimental conditions, including catalyst concentration, the intensity of UV-A radiation and the reactor geometry. The study of the photocatalytic disinfection process at multiple scales, as shown in this work, will be useful in developing more holistic models for photocatalytic disinfection kinetics [38]. The studies referenced in Figure S2 as well as the current work investigate the disinfection kinetics in isolation, as they study the inactivation rates of $E$. coli in absence of any other contaminants in the water. The photocatalytic disinfection of water from actual ground and surface water sources, as well as wastewater, needs consideration of the effects of total organic carbon (TOC) and the presence of various salts in the water as reported by Abidi et al. [39], Moncayo-Lasso et al. [40] and Birben et al. [41]. However, such studies need to be performed on a larger scale to better understand the challenges of scaling up the photocatalytic disinfection process.

The lower rates of inactivation of $E$. coli in the presence of photoactivated porous $\mathrm{TiO}_{2}$ nanowires relative to those observed with Aeroxide ${ }^{\circledR} \mathrm{P} 25$ nanoparticles are believed to be because of the lower specific surface areas of the porous $\mathrm{TiO}_{2}$ nanowires, as well as the lack of access to the surface sites for bacterial inactivation, due to the nanoporous nature of nanowire surfaces (the surfaces have pores of sizes on the order of a few nanometers) [30]. Surface area analysis by the Brunauer-Emmett-Teller (BET) method indicated that porous $\mathrm{TiO}_{2}$ nanowires have a specific surface area of $26.11 \mathrm{~m}^{2} / \mathrm{g}$, lower than the $50-60 \mathrm{~m}^{2} / \mathrm{g}$ of Aeroxide ${ }^{\circledR}$ P25 nanoparticles. The changes in the surfaces areas and the morphologies of the two photocatalysts are also believed to have led to differences in the magnitudes of the UV-A light absorbed, and this manifested as differences in the rates of E. coli inactivation of the two different photocatalysts. UV-vis absorption spectra (Figure S3) for $0.05 \mathrm{~g} / \mathrm{L}$ suspensions of both the porous $\mathrm{TiO}_{2}$ nanowires and the Aeroxide ${ }^{\circledR} \mathrm{P}^{2} \mathrm{TiO}_{2}$ nanoparticles indicated that they both absorb UV-A light (i.e., light in the 315-400 nm range). It is essential to add here that lower concentrations of the photocatalysts were employed for the UV-vis study, as higher concentrations did not allow for obtaining any discernible transmission of light for obtaining the UV-vis spectra. In all, the studies indicated that efficiencies of photocatalytic disinfection of water achieved using small-scale experimentations are replicable in a benchtop setup and that it is possible to accomplish the continuous disinfection of water using photocatalysis.

To understand the recovery, regeneration and reuse of the photocatalyst, the following experiments were performed. The water from the photocatalytic disinfection experiments was autoclaved first to begin the photocatalyst recovery process. To separate the photocatalyst from water, a combination of gravity-assisted settling and centrifugation was employed. The suspensions of E. coli and catalyst from the reactor were collected in two $4 \mathrm{~L}$ polypropylene containers and autoclaved for $1 \mathrm{~h}$ at $121^{\circ} \mathrm{C}$. These suspensions were allowed to rest for 1 day to both cool the solutions down to room temperature and also provide time for the photocatalyst to settle (by gravity) and collect at the bottom of the container. The supernatant water was then decanted from the containers carefully, without 
disturbing the sedimented photocatalyst. This reduced the total volume of the disinfected water to about $0.5 \mathrm{~L}$ from the initial volume of $7 \mathrm{~L}$. This suspension was then centrifuged at $3000 \mathrm{RCF}$ for $10 \mathrm{~min}$ using $50 \mathrm{~mL}$ vortex tubes. The supernatant was again removed and the solutions were then centrifuged again to create new supernatant suspensions of much higher concentrations of photocatalysts. By the end, a $50 \mathrm{~mL}$ highly concentrated suspension of the photocatalyst was obtained. These highly concentrated suspensions were transferred to aluminum weighing dishes and heated for a day in an oven at $60{ }^{\circ} \mathrm{C}$ to remove any remaining water and recover the solid photocatalyst. The recovered photocatalyst was then crushed into finer particles using a mortar and pestle. This crushed catalyst was then regenerated, i.e., its surface was decarburized using air plasma. For this purpose, low-pressure plasmas generated using a basic plasma cleaner (from Harrick Plasma, Ithaca, NY USA) was employed. The ground photocatalyst that was recovered was spread on a petri dish and exposed to air plasmas for a duration of $30 \mathrm{~min}$. Overall, 77\% of the Aeroxide ${ }^{\circledR}$ P25 nanoparticle and $57 \%$ of the $\mathrm{TiO}_{2}$ porous nanowire photocatalysts were recovered in our experiments. Further optimization of the process, including the use of inline centrifuges, could be employed to recover a majority of the photocatalysts in a continuous manner from continuous flow-based photocatalytic reactors.

Of key interest is the determination of the efficacy of the recovered photocatalyst. Experimentation performed to determine the kinetics of disinfection of the recovered and regenerated photocatalysts (Figure 3 ) showed that as-recovered Aeroxide ${ }^{\circledR}$ P25 nanoparticles required a time of $60 \mathrm{~min}$ to achieve a three-order-of-magnitude reduction in E. coli. Upon regeneration of the as-recovered catalyst with plasma treatment, the photoactivity increased and led to a four-order-of-magnitude reduction in E. coli in the same 60 min time span (Figure 3a). The experimentation also indicated that as-recovered porous $\mathrm{TiO}_{2}$ nanowires required a time of $120 \mathrm{~min}$ to reduce $E$. coli by one order of magnitude (Figure 3b). Plasma cleaning of the as-recovered porous $\mathrm{TiO}_{2}$ nanowires' surfaces for regenerating them aided in increasing the photocatalytic activity of the nanowires, leading to a two-order decrease in $E$. coli in a span of $120 \mathrm{~min}$. In both cases, the photoactivity of the regenerated catalyst when inactivating $E$. coli was lower than that of the respective original photocatalysts. However, the reduction in photoactivity was more pronounced for porous $\mathrm{TiO}_{2}$ nanowires, relative to that observed in Aeroxide ${ }^{\circledR}$ P25 nanoparticles. A BET surface area analysis of the recovered and regenerated photocatalysts was performed to document surface area changes in the recovered and regenerated photocatalysts. In the case of nanoparticles, agglomeration and/or surface contamination reduced the surface area from $50-60 \mathrm{~m}^{2} / \mathrm{g}$ to $32.97 \mathrm{~m}^{2} / \mathrm{g}$. Upon plasma cleaning of the recovered Aeroxide ${ }^{\circledR}$ P25 nanoparticles, the available surface area increased from $32.97 \mathrm{~m}^{2} / \mathrm{g}$ to $40.06 \mathrm{~m}^{2} / \mathrm{g}$. This trend is in line with the $E$. coli inactivation kinetics trends described above. However, in the case of porous $\mathrm{TiO}_{2}$ nanowires, the surface area of the recovered nanowires was estimated to be $25.09 \mathrm{~m}^{2} / \mathrm{g}$, much closer to that of the original nanowires of $26.11 \mathrm{~m}^{2} / \mathrm{g}$. The plasma regeneration of the surfaces in this case only resulted in a negligible increase in the available surface areas from $25.09 \mathrm{~m}^{2} / \mathrm{g}$ to $25.14 \mathrm{~m}^{2} / \mathrm{g}$. This result is also supported by the morphology analysis of the $\mathrm{TiO}_{2}$ porous nanowires before and after their use as photocatalysts (Figure S4). SEM micrographs of the $\mathrm{TiO}_{2}$ porous nanowires before (Figure S4a) and after (Figure S4b) their use in photocatalysis indicated no major changes to the nanowire morphology or the nanowire dimensions. While this clearly indicates that agglomeration and loss of surface area is not a major problem in anisotropic shaped photocatalysts, such as nanowires, and that the recovery and regeneration of the photocatalysts is possible, it does not explain why the photoactivity of porous $\mathrm{TiO}_{2}$ nanowires is lost upon recovery and regeneration despite no loss of surface area. Further optimization of the plasma cleaning process, including using higher power plasmas for removing any adventitious carbon on nanowire surfaces, is necessary to ensure that the photocatalysts are completely regenerated. 


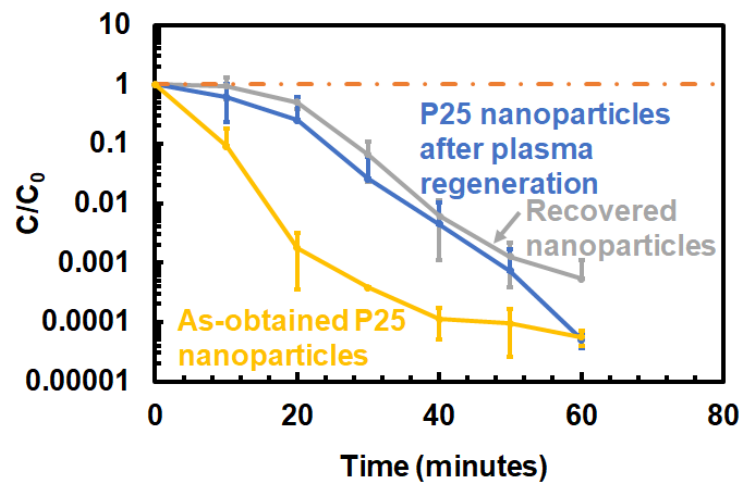

(a)

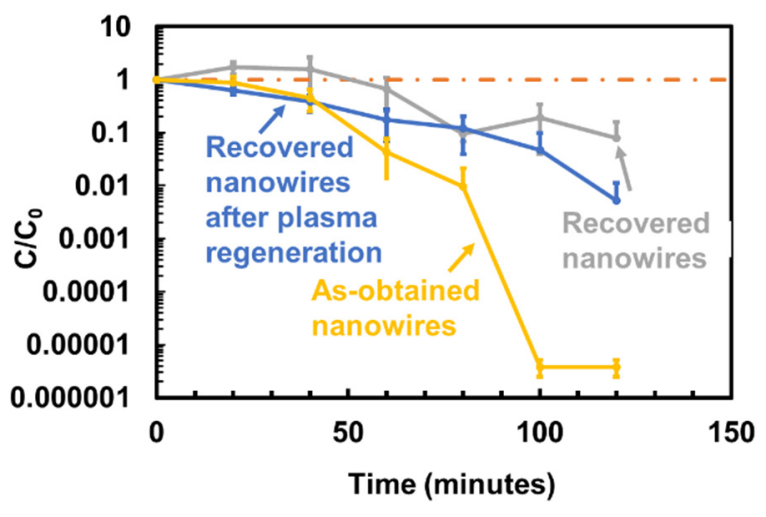

(b)

Figure 3. Kinetics of E. coli disinfection in recovered and regenerated photocatalysts for: (a) Aeroxide P25 $5^{\circledR}$ nanoparticles; (b) $\mathrm{TiO}_{2}$ porous nanowires. In both cases, regeneration of the photocatalyst surfaces using plasmas resulted in the increase in the photocatalyst disinfection kinetics, compared to their as-recovered counterparts.

Finally, experiments were performed to understand the effect of photocatalytic inactivation of E. coli on their ability to reactivate through dark repair. The intent here is that this data sheds light on the maximum time disinfected water could be stored before use, in the absence of any residual disinfection. Regrowth experimentation primarily involved collecting water from the outlet of the disinfection tank and quantifying the E. coli levels in that water, followed by its storage at room temperature for 5 days. The samples were stored under dark conditions to negate the effects of any unintended photodisinfection. Samples were then drawn at various time intervals and characterized for E. coli counts.

E. coli counts were obtained not only in water samples treated by photocatalysis, but also control samples, and depicted in Figure 4. For additional comparison purposes, water containing E. coli was also aged alongside the treated water samples and the control samples, and its E. coli concentrations was also obtained at regular intervals of time. As observed in Figure $4 b, c$, slight reduction on the order of 1-log or lower was observed in both the dark and clear controls. Lack of growth media is believed to be responsible for this reduction in E. coli values. In sharp contrast, the E. coli concentrations remained below the detection limits in water treated by porous $\mathrm{TiO}_{2}$ nanowire photocatalysts. These results clearly demonstrate that dark repair and reactivation of $E$. coli in water disinfected by photocatalysis did not occur within the 5 -day storage period employed in the current study. 


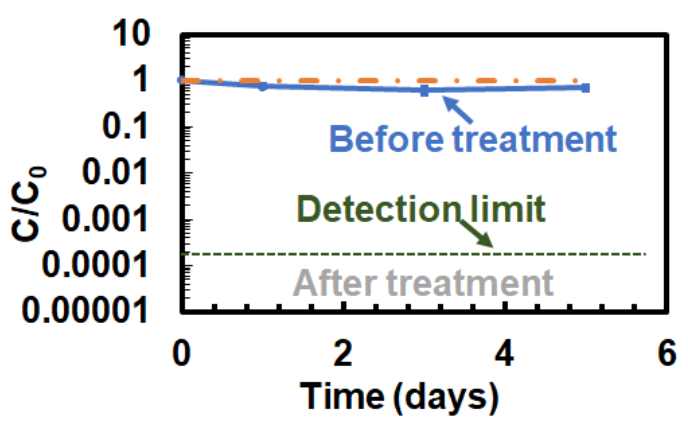

(a)

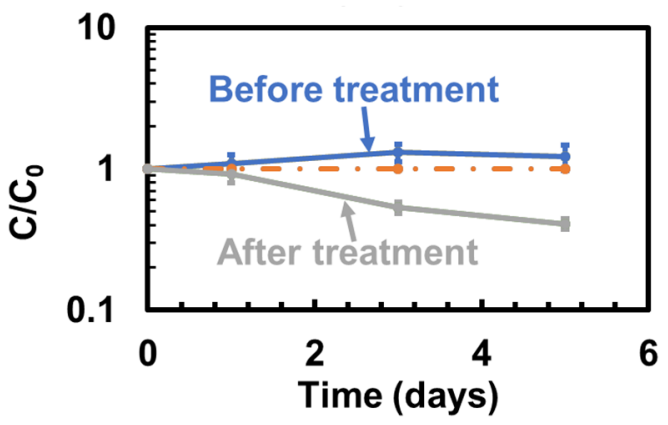

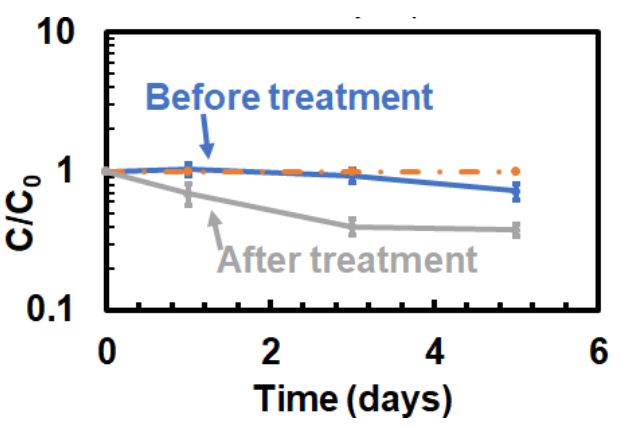

(b)

(c)

Figure 4. Dark repair experimentation plots indicating the concentration of $E$. coli in water vs. time for water stored in the dark following treatment using the following conditions: (a) photocatalysis using porous $\mathrm{TiO}_{2}$ nanowires, (b) exposure to nanowires that are not excited with UV light (dark control) and (c) exposure to UV light in the absence of photocatalysts (clear control). In all the plots, "before treatment" indicates the concentration of E. coli in water samples that did not undergo any treatment, but aged in a similar manner as the treated samples.

\section{Conclusions}

Two major aspects associated with the development of photocatalysis as a process for the large-scale disinfection of water were addressed in this study, namely (a) the use photocatalysis for processing large quantities of water and (b) the recovery, regeneration and reuse of the photocatalysts. The results indicated that the photocatalytic disinfection kinetics achieved by beaker-and-bottle experimentation are replicated in a benchtop system capable of processing 15.14 L (4 gallons) of water per minute. The benchtop system built for this purpose is comprised of only commercially available components, is mobile and could be retrofitted into the water treatment trains currently used for processing wastewater. Moreover, experimentation in this study indicated that gravity-assisted settling, centrifugation and air plasma surface cleaning could be used to recover and regenerate the photocatalyst for its subsequent use in disinfecting additional quantities of water. Not only are the photocatalyst recovery and regeneration processes scalable, but also rapid. Such a rapid recovery and reuse of photocatalyst is critical for the deployment of photocatalysis as a process useful for water disinfection.

Supplementary Materials: The following are available online at https: / www.mdpi.com/article / 10.3390/w13192623/s1, Figure S1: A plot indicating the kinetics of E. coli inactivation in the beaker-scale water disinfection system. Figure S2: Comparison of kinetics for the disinfection of E. coli using $\mathrm{TiO}_{2}$ Aeroxide ${ }^{\circledR} \mathrm{P} 25$ as the photocatalyst activated using the following light sources. Figure S3: UV-Vis absorption spectra for (a) $\mathrm{TiO}_{2}$ Aeroxide ${ }^{\circledR} \mathrm{P} 25$ nanoparticles and (b) $\mathrm{TiO}_{2}$ porous nanowires. Figure S4: A comparison of morphologies of (a) as-obtained $\mathrm{TiO}_{2}$ porous nanowires, and (b) $\mathrm{TiO}_{2}$ nanowires recovered after photocatalysis.

Author Contributions: Conceptualization, S.V. and T.G.; methodology, T.G., S.V., N.A.V. and J.B.; formal analysis, T.G., S.V., N.A.V. and J.B.; investigation, T.G., S.V., N.A.V. and J.B.; resources, S.V. and T.G.; data curation, T.G., S.V., N.A.V. and J.B.; writing-original draft preparation, S.V.; writing- 
review and editing, T.G., S.V., N.A.V. and J.B.; visualization, N.A.V. and J.B.; supervision, S.V. and T.G.; project administration, S.V. and T.G.; funding acquisition, S.V. and T.G. All authors have read and agreed to the published version of the manuscript.

Funding: This research was partially funded by Agriculture and Food Research Initiative Competitive Grant no. 2018-67016-27578 awarded as a Center of Excellence from the USDA National Institute of Food and Agriculture. This project was also partially supported by the Research, Engineering and Extension: Creation and Deployment of Water-Use Efficient Technology Platforms “Water Seed Grant Initiative" by Texas A\&M University System.

Institutional Review Board Statement: Not applicable.

Informed Consent Statement: Not applicable.

Data Availability Statement: The data presented in this study are available on request from the corresponding author.

Acknowledgments: The authors wish to acknowledge the help of Hae-Kwon Jeong (in the Artie McFerrin Department of Chemical Engineering at Texas A\&M University) and his graduate student, Yinying Hua, with the BET measurements of the surface areas of various photocatalysts and John Boswell for assistance with the microbial measurements.

Conflicts of Interest: The authors declare no conflict of interest.

\section{References}

1. Drinan, J.; Spellman, F.R.; Drinan, J. Water and Wastewater Treatment: A Guide for the Nonengineering Professional, 2nd ed.; CRC Press: Boca Raton, FL, USA, 2000.

2. Loeb, S.K.; Alvarez, P.J.J.; Brame, J.A.; Cates, E.L.; Choi, W.; Crittenden, J.; Dionysiou, D.D.; Li, Q.; Li-Puma, G.; Quan, X.; et al. The Technology Horizon for Photocatalytic Water Treatment: Sunrise or Sunset? Environ. Sci. Technol. 2019, 53, $2937-2947$. [CrossRef] [PubMed]

3. Boretti, A.; Rosa, L. Reassessing the projections of the world water development report. NPJ Clean Water 2019, 2, 1-6. [CrossRef]

4. Byrne, J.A.; Dunlop, P.S.M.; Hamilton, J.W.J.; Fernández-Ibáñez, P.; Polo-López, I.; Sharma, P.K.; Vennard, A.S.M. A review of heterogeneous photocatalysis for water and surface disinfection. Molecules 2015, 20, 5574-5615. [CrossRef] [PubMed]

5. Chong, M.N.; Jin, B.; Chow, C.W.; Saint, C. Recent developments in photocatalytic water treatment technology: A review. Water Res. 2010, 44, 2997-3027. [CrossRef] [PubMed]

6. Foster, H.A.; Ditta, I.B.; Varghese, S.; Steele, A. Photocatalytic disinfection using titanium dioxide: Spectrum and mechanism of antimicrobial activity. Appl. Microbiol. Biotechnol. 2011, 90, 1847-1868. [CrossRef] [PubMed]

7. Cates, E.L. Photocatalytic Water Treatment: So Where Are We Going with This? Environ. Sci. Technol. 2017, 51, 757-758. [CrossRef] [PubMed]

8. Schneider, J.; Matsuoka, M.; Takeuchi, M.; Zhang, J.; Horiuchi, Y.; Anpo, M.; Bahnemann, D.W. Understanding TiO 2 photocatalysis: Mechanisms and materials. Chem. Rev. 2014, 114, 9919-9986. [CrossRef] [PubMed]

9. Zhang, C.; Li, Y.; Shuai, D.; Shen, Y.; Wang, D. Progress and challenges in photocatalytic disinfection of waterborne viruses: A review to fill current knowledge gaps. Chem. Eng. J. 2019, 355, 399-415. [CrossRef]

10. Zhao, W.; Chen, I.-W.; Huang, F. Toward large-scale water treatment using nanomaterials. Nano Today 2019, 27, 11-27. [CrossRef]

11. Alrousan, D.; Polo-López, M.; Dunlop, P.; Fernández-lbáñez, P.; Byrne, J. Solar photocatalytic disinfection of water with immobilised titanium dioxide in re-circulating flow CPC reactors. Appl. Catal. B Environ. 2012, 128, 126-134. [CrossRef]

12. Yu, H.; Song, L.; Hao, Y.; Lu, N.; Quan, X.; Chen, S.; Zhang, Y.; Feng, Y. Fabrication of pilot-scale photocatalytic disinfection device by installing $\mathrm{TiO} 2$ coated helical support into UV annular reactor for strengthening sterilization. Chem. Eng. J. 2016, 283, 1506-1513. [CrossRef]

13. Saran, S.; Arunkumar, P.; Manjari, G.; Devipriya, P.S. Reclamation of grey water for non-potable purposes using pilot-scale solar photocatalytic tubular reactors. Environ. Technol. 2019, 40, 3190-3199. [CrossRef] [PubMed]

14. Fernández-Ibáñez, P.; Blanco, J.; Malato, S.; de las Nieves, F. Application of the colloidal stability of $\mathrm{TiO}_{2}$ particles for recovery and reuse in solar photocatalysis. Water Res. 2003, 37, 3180-3188. [CrossRef]

15. Kacem, M.; Plantard, G.; Brienza, M.; Goetz, V. Continuous-Flow Aqueous System for Heterogeneous Photocatalytic Disinfection of Gram-Negative Escherichia coli. Ind. Eng. Chem. Res. 2017, 56, 15001-15007. [CrossRef]

16. Pozzo, R.L.; Giombi, J.L.; Baltanás, M.A.; Cassano, A.E. The performance in a fluidized bed reactor of photocatalysts immobilized onto inert supports. Catal. Today 2000, 62, 175-187. [CrossRef]

17. Chong, M.N.; Lei, S.; Jin, B.; Saint, C.; Chow, C.W. Optimisation of an annular photoreactor process for degradation of Congo Red using a newly synthesized titania impregnated kaolinite nano-photocatalyst. Sep. Purif. Technol. 2009, 67, 355-363. [CrossRef]

18. Ochuma, I.J.; Fishwick, R.P.; Wood, J.; Winterbottom, J.M. Optimisation of degradation conditions of 1, 8-diazabicyclo [5.4. 0] undec-7-ene in water and reaction kinetics analysis using a cocurrent downflow contactor photocatalytic reactor. Appl. Catal. B Environ. 2007, 73, 259-268. [CrossRef] 
19. Fu, J.; Ji, M.; Wang, Z.; Jin, L.; An, D. A new submerged membrane photocatalysis reactor (SMPR) for fulvic acid removal using a nano-structured photocatalyst. J. Hazard. Mater. 2006, 131, 238-242. [CrossRef]

20. Alalm, M.G.; Djellabi, R.; Meroni, D.; Pirola, C.; Bianchi, C.L.; Boffito, D.C. Toward Scaling-Up Photocatalytic Process for Multiphase Environmental Applications. Catalysts 2021, 11, 562. [CrossRef]

21. Piera, E.; Ayllón, J.A.; Doménech, X.; Peral, J. $\mathrm{TiO}_{2}$ deactivation during gas-phase photocatalytic oxidation of ethanol. Catal. Today 2002, 76, 259-270. [CrossRef]

22. van Dijk, V.H.; Simmelink, G.; Mul, G. The influence of water vapour on the photocatalytic oxidation of cyclohexane in an internally illuminated monolith reactor. Appl. Catal. A Gen. 2014, 470, 63-71. [CrossRef]

23. Walenta, C.A.; Kollmannsberger, S.L.; Kiermaier, J.; Winbauer, A.; Tschurl, M.; Heiz, U. Ethanol photocatalysis on rutile TiO 2 (110): The role of defects and water. Phys. Chem. Chem. Phys. 2015, 17, 22809-22814. [CrossRef] [PubMed]

24. Akpan, U.G.; Hameed, B.H. Parameters affecting the photocatalytic degradation of dyes using $\mathrm{TiO}_{2}$-based photocatalysts: A review. J. Hazard. Mater. 2009, 170, 520-529. [CrossRef] [PubMed]

25. Fagan, R.; McCormack, D.E.; Dionysiou, D.D.; Pillai, S.C. A review of solar and visible light active $\mathrm{TiO}_{2}$ photocatalysis for treating bacteria, cyanotoxins and contaminants of emerging concern. Mater. Sci. Semicond. Process. 2016, 42, 2-14. [CrossRef]

26. Chatzisymeon, E.; Droumpali, A.; Mantzavinos, D.; Venieri, D. Disinfection of water and wastewater by UV-A and UV-C irradiation: Application of real-time PCR method. Photochem. Photobiol. Sci. 2011, 10, 389-395. [CrossRef] [PubMed]

27. Kumar, V.; Kim, J.H.; Jasinski, J.B.; Clark, E.L.; Sunkara, M.K. Alkali-Assisted, Atmospheric Plasma Production of Titania Nanowire Powders and Arrays. Cryst. Growth Des. 2011, 11, 2913-2919. [CrossRef]

28. Nguyen, T.Q.; Atla, V.; Vendra, V.K.; Thapa, A.K.; Jasinski, J.B.; Druffel, T.L.; Sunkara, M.K. Scalable solvo-plasma production of porous tin oxide nanowires. Chem. Eng. Sci. 2016, 154, 20-26. [CrossRef]

29. Kumar, V.; Kim, J.H.; Pendyala, C.; Chernomordik, B.; Sunkara, M.K. Gas-Phase, Bulk Production of Metal Oxide Nanowires and Nanoparticles Using a Microwave Plasma Jet Reactor. J. Phys. Chem. C 2008, 112, 17750-17754. [CrossRef]

30. Afreen, G.; Lara-Ramos, J.A.; Vidwans, N.A.; Atla, V.; Kumar, V.; Vaddiraju, S.; Machuca-Martinez, F.; Sunkara, M.K.; Upadhyayula, S. Bulk production of porous $\mathrm{TiO}_{2}$ nanowires by unique solvo-plasma oxidation approach for combating biotic and abiotic water contaminants. J. Mater. Sci. Mater. Electron. 2021, 32, 21974-21987. [CrossRef]

31. Benabbou, A.; Derriche, Z.; Felix, C.; Lejeune, P.; Guillard, C. Photocatalytic inactivation of Escherischia coli: Effect of concentration of $\mathrm{TiO}_{2}$ and microorganism, nature, and intensity of UV irradiation. Appl. Catal. B Environ. 2007, 76, 257-263. [CrossRef]

32. Cho, M.; Chung, H.; Choi, W.; Yoon, J. Different inactivation behaviors of MS-2 phage and Escherichia coli in $\mathrm{TiO}_{2}$ photocatalytic disinfection. Appl. Environ. Microbiol. 2005, 71, 270-275. [CrossRef] [PubMed]

33. Ibáñez, J.A.; Litter, M.I.; Pizarro, R.A. Photocatalytic bactericidal effect of $\mathrm{TiO}_{2}$ on Enterobacter cloacae: Comparative study with other Gram (-) bacteria. J. Photochem. Photobiol. A Chem. 2003, 157, 81-85. [CrossRef]

34. Khraisheh, M.; Wu, L.; Ala'a, H.; Al-Ghouti, M.A. Photocatalytic disinfection of Escherichia coli using TiO $2 \mathrm{P}^{25}$ and Cu-doped $\mathrm{TiO}_{2}$. J. Ind. Eng. Chem. 2015, 28, 369-376. [CrossRef]

35. Maness, P.-C.; Smolinski, S.; Blake, D.M.; Huang, Z.; Wolfrum, E.J.; Jacoby, W.A. Bactericidal activity of photocatalytic TiO 2 reaction: Toward an understanding of its killing mechanism. Appl. Environ. Microbiol. 1999, 65, 4094-4098. [CrossRef]

36. McCullagh, C.; Robertson, J.M.; Bahnemann, D.W.; Robertson, P.K. The application of $\mathrm{TiO}_{2}$ photocatalysis for disinfection of water contaminated with pathogenic micro-organisms: A review. Res. Chem. Intermed. 2007, 33, 359-375. [CrossRef]

37. Rincón, A.-G.; Pulgarin, C. Comparative evaluation of $\mathrm{Fe}^{3+}$ and $\mathrm{TiO}_{2}$ photoassisted processes in solar photocatalytic disinfection of water. Appl. Catal. B Environ. 2006, 63, 222-231. [CrossRef]

38. Bloh, J.Z. A holistic approach to model the kinetics of photocatalytic reactions. Front. Chem. 2019, 7, 128. [CrossRef]

39. Abidi, M.; Hajjaji, A.; Bouzaza, A.; Trablesi, K.; Makhlouf, H.; Rtimi, S.; Assadi, A.; Bessais, B. Simultaneous removal of bacteria and volatile organic compounds on $\mathrm{Cu}_{2} \mathrm{O}-\mathrm{NPs}$ decorated $\mathrm{TiO}_{2}$ nanotubes: Competition effect and kinetic studies. J. Photochem. Photobiol. A Chem. 2020, 400, 112722. [CrossRef]

40. Moncayo-Lasso, A.; Mora-Arismendi, L.E.; Rengifo-Herrera, J.A.; Sanabria, J.; Benítez, N.; Pulgarin, C. The detrimental influence of bacteria (E. coli, Shigella and Salmonella) on the degradation of organic compounds (and vice versa) in $\mathrm{TiO}_{2}$ photocatalysis and near-neutral photo-Fenton processes under simulated solar light. Photochem. Photobiol. Sci. 2012, 11, 821-827. [CrossRef]

41. Birben, N.C.; Uyguner-Demirel, C.S.; Bekbolet, M. Photocatalytic removal of microbiological consortium and organic matter in greywater. Catalysts 2016, 6, 91. [CrossRef] 